Portland State University

PDXScholar

$5-1-1991$

\title{
A Comparison of the Vocabulary Needs of Speaking and Nonspeaking Twins
}

Dana Lynette Hamburg

Portland State University

Follow this and additional works at: https://pdxscholar.library.pdx.edu/open_access_etds

Part of the Speech and Hearing Science Commons

Let us know how access to this document benefits you.

\section{Recommended Citation}

Hamburg, Dana Lynette, "A Comparison of the Vocabulary Needs of Speaking and Nonspeaking Twins" (1991). Dissertations and Theses. Paper 4186.

https://doi.org/10.15760/etd.6070

This Thesis is brought to you for free and open access. It has been accepted for inclusion in Dissertations and Theses by an authorized administrator of PDXScholar. Please contact us if we can make this document more accessible: pdxscholar@pdx.edu. 
AN ABSTRACT OF THE THESIS OF Dana Lynette Hamburg for the Master of Science in Speech Communication: Speech and Hearing Sciences presented May 1, 1991.

Title: A Comparison of the Vocabulary Needs of speaking and Nonspeaking Twins.

APPROVED BY THE MEMBERS OF THE THESIS COMMITTEE:

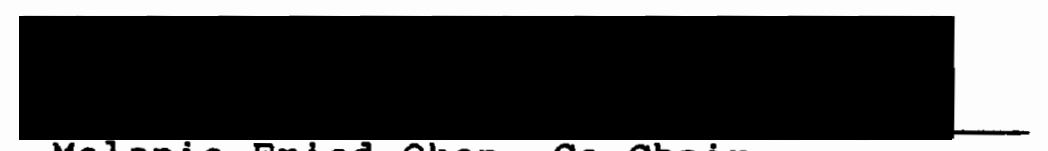

Melanie Fried-oken, Co-Chair

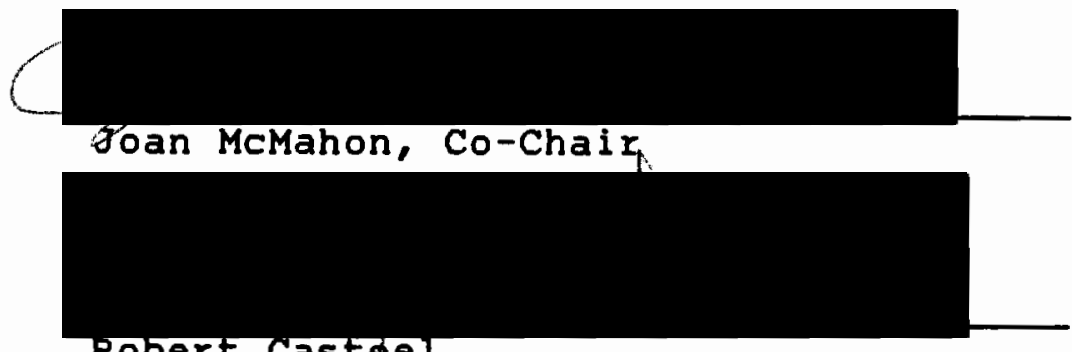

Robert castee1

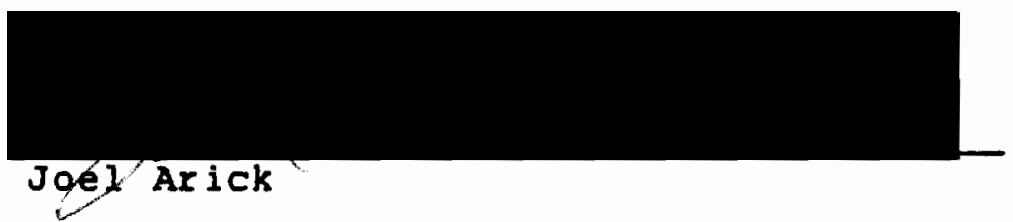

Children with severe physical disabilities often do not have the capabilities for oral communication. Therefore, the vocabulary needs of nonspeaking children has been a subject of research in the area of augmentative communication for a number of years. The idea of allowing children with disabilities the opportunity for expression and 
communication is one not easily ignored. Obtaining vocabulary items, however, that are useful to nonspeaking disabled children that also meet normal language acquisition standards has been a concern. This study specifically addresses this concern by looking into the vocabulary issues of twins. The purpose of this research project is to verify that differences exist in the expressive vocabulary needs that are determined for a nonspeaking, cerebral-palsied twin and a speaking, able-bodied twin by a careglver despite similar verbal environments.

six twin pairs were used. One of the twins in each pair was normally developing in respect to cognition, sensory abilities and speech/language. The other twin had both a nonambulatory and nonspeaking condition. Their ages range between $3 ; 2$ and $10 ; 11$ years with four male twin pairs and two female twin pairs. The procedures included a 100word parent-selected vocabulary list for each twin which was to be representative of the words each child requires to communicate effectively. Additionally a 1000-word language sample of the speaking twin within each twin pair was obtained during a play activity. The vocabulary items obtained were then compared to answer the following questions: 1) What is the percentage lexical agreement between the parent's vocabulary lists for the speaking and nonspeaking twin?; 2) what is the percentage of lexical agreement between the language sample of the speaking twin 
and the parent's vocabulary lists for that child and the nonspeaking twin?; 3 ) What vocabulary items constitute a composite vocabulary list of common words selected by the parents for each twin and the words actualiy spoken by the normal twin?

Results indicate that 508 of the words chosen by the parent for the nonspeaking twin were also chosen for the speaking twin. This split percentage suggests that parents indeed address normal language acquisition, while not ignoring the unique words necessary to meet the needs of their disabled chlld. Additionally, low percentages were obtained when the words in the parent-selected 1 ists and the language sample were compared. The words chosen for the nonspeaking twins, however, presented slightly lower percentage agreements than the speaking twins. The lower agreement of vocabulary items reflects the different lexical items needed for the nonspeaking, nonambulatory child that may not occur in the language sample of a normally developing child during a play activity. Therefore, this research profect demonstrates that despite similar verbal environments, the words chosen for twins varies with the abilities and needs of each child, as well as other situational influences.

The lexical items comprising the twin composite vocabulary lists satisfy the various areas for semantic content categories and communicative functions. Further- 
more, these words seem to be especlally relevant since they not only represent words from normal language acquisition, but also meet the needs of nonspeaking physically disabled chilaren. 
A COMPARISON OF THE VOCABULARY NEEDS OF

SPEAKING AND NONSPEAKING TWINS

by

DANA LYNETTE HAMBURG

A thesis submitted in partial fulfillment of the requirements for the degree of

\author{
MASTER OF SCIENCE \\ in \\ SPEECH COMMUNICATION : \\ SPEECH AND HEARING SCIENCE
}

Portland State University

1991 
TO THE OFFICE OF GRADUATE STUDIES :

The members of the Committee approve the thesis of Dana Lynette Hamburg presented May 1, 1991.

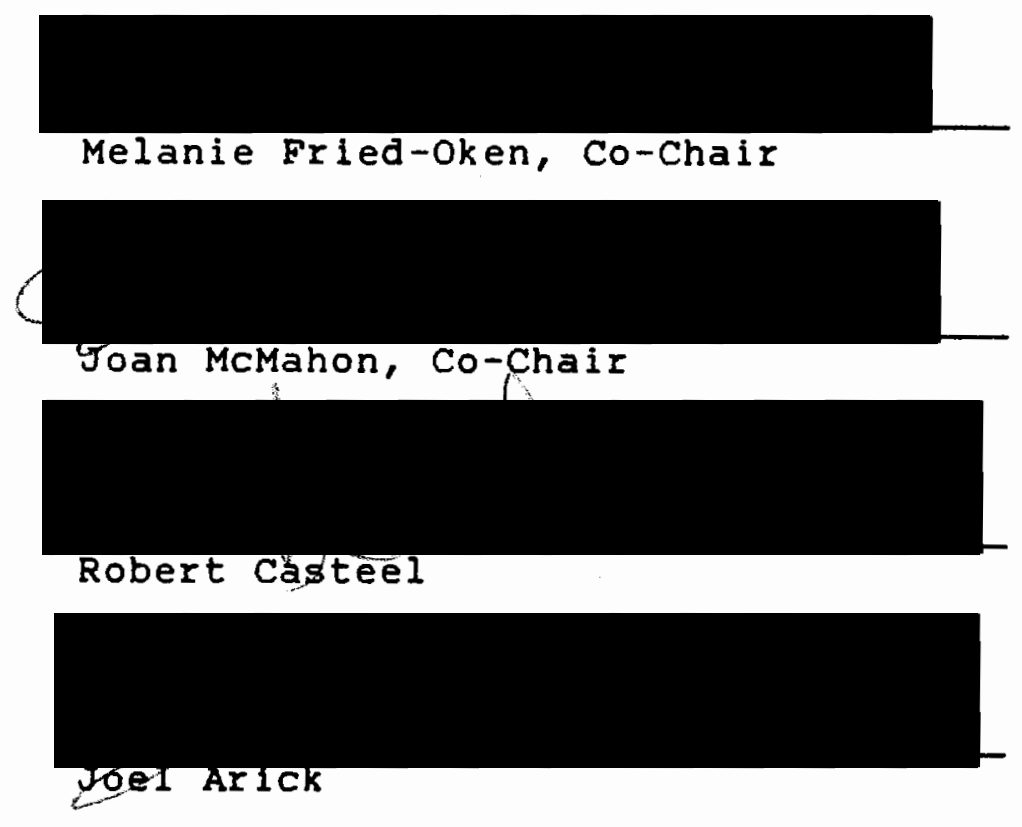

\section{APPROVED :}
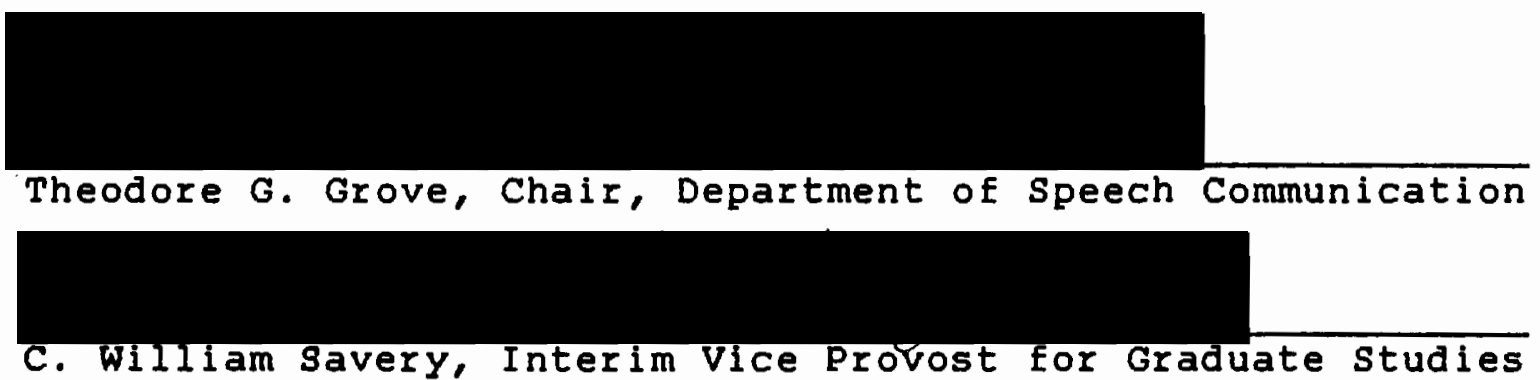
and Research 


\section{ACKNOWLEDGEMENTS}

Thanks to Dr. Melanie Fried-oken and Lillian More for getting me started in this research project and for their initial work and research contribution. I especially appreciate Melanie's faith and never ending encouragement in my abilities as an amateur researcher. I would also like to thank my advisor, Joan McMahon, and the other members of my thesis committee, Dr. Robert Casteel and Dr. Joel Arick. 
TABLE OF CONTENTS

PAGE

ACKNOWLEDGEMENTS . . . . . . . . . . . . . . . . . . ii

LIST OF TABLES. . . . . . . . . . . . . . . . . . . . vi

CHAPTER

I INTRODUCTION AND STATEMENT OF PURPOSE. . . . . . . 1

Introduction. . . . . . . . . . . . . . . . 1

Statement of Purpose. . . . . . . . . . 2

Definition of Terms . . . . . . . . . . . . 3

I I REVIEW OF THE IITERATURE . . . . . . . . . . . . . 4

Communicative Environment and Language

Learning

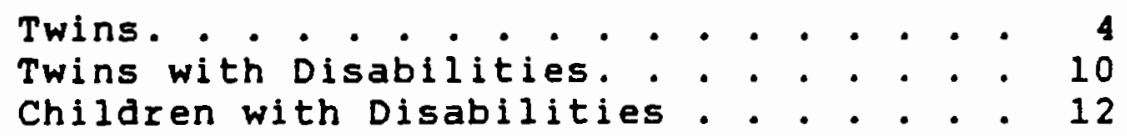

Strategies for Vocabulary Selection . . . . . 17

summary . . . . . . . . . . . . . . 21

II METHODS. . . . . . . . . . . . . . . . 22

Subjects and Selection Procedures . . . . . 22

Data Collection. . . . . . . . . . . . . 24

Data Entry. . . . . . . . . . . . . 26

Data Analysis... . . . . . . . . . . 26 
IV RESULTS AND DISCUSSION . . . . . . . . . . . . . . 29

Results. . . . . . . . . . . . . . 29

Discussion. . . . . . . . . . . . . 37

$\mathrm{V}$ SUMMARY AND IMPLICATIONS . . . . . . . . . . . . . 46

summary . . . . . . . . . . . . . . . . . . 46

Clinical Implications. . . . . . . . . . 48

Research Implications . . . . . . . . . 50

REFERENCES. . . . . . . . . . . . . . . . . 53

APPENDICES

A PARENT AND CLINICIAN COVER LETTER . . . . . . 57

B INFORMED CONSENT FORM . . . . . . . . . . 62

C PARENT VOCABULARY FORMS . . . . . . . . . 66

D GUIDELINES FOR COLLECTING LANGUAGE SAMPLES. . 74

E PROCEDURES FOR SELECTING 100 SINGLE WORDS FROM THE 110-WORD VOCABULARY LIST . . . . . 76

F TRANSCRIPTION AND EDITING GUIDELINES. . . . . 78 


\section{LIST OF TABLES}

TABLE

PAGE

I subject status. . . . . . . . . . . . . . 22

I AAC System Use by Disabled Twin . . . . . . . . . 24

II Percent Lexical Agreement Between Parent Lists. . 30

IV List Sizes and Number of Unique Words for

Language Sample. . . . . . . . . . . 32

$\checkmark$ 2-Way Comparisons: Percent Lexical Agreement Between

Parent Lists and Language Sample . . . . . 33

VI 3-Way Comparisons: Composite Vocabulary List

for Each Twin pair . . . . . . . . . . 36 


\section{CHAPTER I \\ INTRODUCTION AND STATEMENT OF PURPOSE}

\section{INTRODUCTION}

Children with severe physical disabilities often do not have the capabilities for oral communication. These disabilities may be the result of cerebral palsy or other congenital anomalies. Whatever the cause, these children are not only limited in the experiences they encounter but also in their interaction with other human beings. Disabled children are easily ignored and isolated. To help remedy this dilemma, research has been conducted into the area of allowing children with disabilities the opportunity for expression and communication. Often the use of augmentative communication devices, such as various types of communication boards are implemented. An unresolved issue, however, has been the selection of vocabulary items to be utilized on these devices. How should we go about choosing the vocabulary? Does one select words geared more toward the daily care and medical needs of the child or word types that Eit into normal vocabulary acquisition? We must consider what words are appropriate to fit that child's needs. In acquiring normal language, a child is in control of what words are chosen to say. A child with a severe oral 
motor disorder is not able to choose those words and needs to rely on an augmentative communication device and the words chosen by others. This lack of control over word environment, as well as the reduced experience of a disabled child, may affect language development (Carlson, 1981). The first words a child learns seem especially important. According to Fried-oken (1989), they establish a sense for "the power of communication, self-concept, language development, and the rules of socialization". If these areas are not considered, a disabled child is further at risk for delays due to various communication barriers.

These issues may be heightened in the case of twins, one being severely disabled and the other normally developing. How does raising a twin pair such as this, in a similar environment, but each having such varying needs influence the interactions and vocabulary used and selected for the two children? This question will be addressed throughout this research project.

\section{STATEMENT OF PURPOSE}

The purpose of this research project is to verify that differences exist in the expressive vocabulary needs that are determined for a nonspeaking, cerebral-palsied twin and a speaking, able-bodied twin by a caregiver despite similar verbal environments. Results of this research will be applied to the development of vocabulary selection guide- 
lines in augmentative and alternative communication for children. To accomplish this goal, the following questions will be answered:

1. What is the percentage lexical agreement between the parent's vocabulary lists for the speaking and nonspeaking twin?

2. What is the percentage of lexical agreement between the language sample of the speaking twin and the parent's vocabulary lists for that child and the nonspeaking twin?

3. What vocabulary items constitute a composite vocabulary list of common words representing the parent selected words for each twin and the words actually spoken by the normal twin will be compiled within twin pairs?

\section{DEFINITION OF TERMS}

The following terms were used as operational definitions for this study:

1. Nonspeaking - A condition where the individual is unable to use oral speech as the primary mode of communication.

2. Nonambulatory - A condition where the individual is unable to use independent ambulation as the primary mode of mobility.

3. Augmentative and Alternative Communication (AAC) Any strategy, technique, or device developed specifically to supplement or replace oral speech for individuals with expressive language impairments (Vanderheiden \& Lloyd, 1986).

4. Cerebral Palsy - Disorders caused by an irregularity in the central nervous system, primarily at the motor control center; damage may be caused at any time before muscular coordination is attained. Characteristics may include too much or too little muscle tone, abnormal positioning, and general lack of coordination. Intellect, speech, hearing, vision, and emotional control may be affected (Shames \& Wiig, 1986, p. 614). 
CHAPTER II

REVIEW OF THE LITERATURE

COMMUNICATIVE ENVIRONMENT AND LANGUAGE LEARNING

\section{Twins}

The environment in which twins learn language is evidently different from that of singleton children (Lytton, Conway, and Sauve, 1977; Tomasel10, Michael, and Kruger, 1986; Malmstrom and Silva, 1986; Stafford, 1987). The communicative environment invariably affects the way in which language is learned, as well as language performance and expression.

Research has shown that twin children may have delayed receptive and expressive language skills compared to children raised singly (Day, 1932; Davis, 1937; Koch, 1966; Stafford, 1987). Lytton, Conway, and Sauve (1977) found that a decrease in expressive language skills in twins correlated with restricted social interaction with the parents. It seems that the parents of twins are reguired to divide their time between the two children. Thus, parents' verbal interactions could not be as extensive and attentive as parents of singleton children. Each child may have less verbal interaction with the parents and be exposed to a limited range of language forms and socialization skills. 
Specifically, twins receive less exposure to directions, commands, verbal justifications, praise and approvals (Lytton et al., 1977). According to Tomasello, Michael and Kruger (1986), the parental responses to the two children are imitative rather than generative or socially interactive, thus attributing to delayed language learning.

Stafford (1987) examined twin language differences to propose a possible reason why they exist. Language comprehension and expression of twins tended to lag behind that of singletons by a few months. She concluded that differences in the maternal input to twins and singletons contributed to the language variations. Maternal use of imitations, expansions, extension and topic continuations were devices rated as highly responsive, informative and helpful in children's language acquisition. Mothers of twins, however, used half as many of these devices as did mothers of single children. The mothers of twins also used more commands, declaratives, and answering of their own questions. These devices were labeled as being negatively associated with language comprehension and expression development. Other characteristic behaviors of mothers of twins included less positive acknowledgements and interaction, as well as conversation with the twins as one unit instead of interacting with each on an individual basis. This may be the result of interacting in triads (mother, twin, twin) the increased time involved with two children of the same age, 
or the fact that since twins have same-aged playmates, parents may feel less demands to interact with the children. stafford reports that "the speech of the mothers of twins can generally be characterized as having a relative lack of responsive and conversation-eliciting features and a relative abundance of nonresponsive features" (p. 456). Thus, how the parents of twins interact and adjust to the twin situation has some influence on how twins learn language.

One must remember that even though twin language tends to be delayed in some characteristics, children reproduce the language forms in which they have been exposed. Best (1988) indicated that the linguistic environment of twins determines language development. By following a set of twins, she came to the conclusion that the language competence of twins is influenced by "individual preferences and personalities" of each child (p. 16). Parents react to any individual differences and then focus and form their language to meet each child's needs according to those differences, thus, the different language performances of twin children. Since the parents have limited time to spenc in meeting one child's language and communication needs, this may be part of the reason for the characteristic delay of language in twins as compared to singleton children. The social development of twins seems to differ from that of singleton children as well. Vandell, Owen, wilson \& 
Henderson (1988) observed twin chlldren as they interacted with their mother, with each other, and with an unfamiliar peer. They concluded that during the first year, no differences in the interactions with each other and an unfamiliar peer were found. Additlonally, a preference emerged in twins who were more likely to interact with each other during the first year were more apt to interact with each other during the second year. One possible reason for this may be that twins understand each other from frequent interaction and therefore tend to have more of an incentive to interact with each other. The security of their relationship with their mother, however, partially determined their responsivity or interaction with each other and with unfamiliar peers. Those twins labeled at six months as having secure maternal attachment were more likely to have a later interest in peer interactions. It is quite possible that early careglver interactions which may inltially determine the level of maternal attachment or security, later determines the interest in peer interaction.

The twin situation brings with it further language characteristics that are unique to the twin relationship. It has been reported that twins may develop their own private language, often termed "idioglossia." This private language has been hypothesized to result from the poor language modeling of twin-twin lnteractions and limited adult models, a continuation of baby-talk within twin pairs, 
the manifestation of increased twin interactions, or to maintain a "sense of symbiosis" (Ainslie, 1985, p.77; Koch, 1966 ; Savic, 1980).

Idioglossia, "autonomous speech" and "secret speech" as it is frequently referred to, has been studied to determine its particular characteristics. Luria and Yudovich (1959), have outlined specifics of this speech and language deviation. They reported that this phenomenon presents a vocabulary differing from that of the normal child's common word forms and a grammar that represents concrete and objective activity as a whole, as opposed to the abstract language system of adults. They also stress that the purpose of this autonomous language is to help organize the children's world and form their reality through the mental processes of language. This phenomenon usually dissipates with the increasing socialization of the twins with other children. Ainslie (1985) reported that this language is usualiy a transient stage that some twins may experience to secure their twin identity by linguistically isolating themselves from caregivers.

Malmstrom and Silva (1986) investigated the language characteristics of one set of twins from the age of 2.0 through 3.9 years. The twins developed normal syntax and vocabulary. Some deviant structures were noted, however. For example, the pronoun "me" was used to represent both children as one unit. When certain items or people were 
grouped in twos, those names were connected as one name, such as "Kelda-Krista", representing the single unit concept again. Singular verbs were used in reference to themselves also.

stafford (1987) reported that twin language was not evident in her study, but suggested that idioglossia could be a function of how interactive the parents are with the twins as individuals. If the mother interacts with them as a unit, the twins become very close in their interactions, which may foster a sense of a single identity. Ainslie (1985) reported that this twin language reflects "a linguistic representation of the intertwin identification" (p. 76).

Munsinger and Douglass (1976), however, presented another variable of language learning. They decided to study whether language skills are the result of heredity or environment in identical and fraternal twins and their siblings. Their findings showed that identical twin pairs' language skills are significantly more similar than that of Eraternal twins or siblings. It also seems that fraternal twin pairs' and their normal siblings' language skills were nearly the same, but that identical twins' language skills were reduced. The authors suggest that this difference between ldentical and fraternal twins is attributed to genetic influence since it is most difficult to conclude that parental treatment of ldentical twins is different to 
that of fraternal twins or their siblings.

The role of the linguistic environment as well as genetics, have been implicated in the language learning of twins. Most likely, it is a combination of both environment and genetics that determine the level of language competence. Let us now turn to the literature concerning twins with disabilities.

\section{Twins with Disabilities}

The degree and style of caregiver's interaction with a child with disabilities can affect the communicative environment, thus influencing the child's linguistic development. Yoder, Earran, and Allen (1984) conducted a study directed at confirming this hypothesis. They compared mother-infant dyads involving two sets of fraternal infant twins, one twin being normal and the other displaying various disabilities. It was concluded that less contingent or responsive behaviors were displayed by the mother when interacting with the disabled twin. The twin with disabilities also spent less time in joint attention and exhibited greater nondirected behaviors. Joint attention, contingent and responsive behaviors on the part of both participants not only seem to enrich social interaction, but also contribute to communicative development (Owens, 1986 ). Thus, the results indicate that the interactions between caregivers and a child with aisabilities might be hindering 
that child's prelinguistic communication skills; the skills that are primary to later effective interpersonal interaction.

When twins are raised with one or both of them being disabled, they miss out on the unique and special twin relationship and situation. Crismore (1982) reported that the parents of twins, one being normal, the other having a spastic condition as well as mentally disabled, experience many dilemmas. Of special interest to this research project, is that these parents felt that most of their anguish resulted from the "spolling of the twin relationship" or "twin experience" (p. 12). Twins growing up so differently, yet in the same environment and having many of the same experlences, may feel "incomplete" as the twin relationship is lost. This twin relationship has also been determined to have more of an influence in "socialization experiences and development" than other factors such as social class (Lytton et al., 1977, p.106).

Penn and Haden (1985) examined the syntactic skills of one normally developing twin and one language-impaired twin. The normal twin was the dominate partner in the dyad, and had the sophisticated syntactic structures present in her repertolre. Also, the normal twin often completed, corrected and explained the utterances of the languageimpaired twin. Upon recelving speech therapy, the languageimpaired twin made gains and the prior communicative 
behaviors became less obvious. It was not discussed explicitly, but one must question whether the prior asymmetrical communicative behaviors existed because of the dominance of the normal twin as a result of the other's language-impairment or because the dominance of the one twin in language interactions inadvertently had an influence upon the other twin's language impairment. This scenario demonstrates that even though one twin may be impaired, they still manage to be linked in their interactlons and maintain the twin identity.

\section{Children with Disabilities}

In a child's acquisition of language, the communicative environment plays an integral role. It includes such elements as physical surroundings and objects, people interacted with, the manner of communication, and the feelings and attitudes of others. The communicative environment can impede or encourage the normal cognitive and expressive language development. A communicatively healthy environment may also foster the concept of socialization and the needed skills for interaction. With a nonspeaking and/or severely disabled child, however, a healthy communicative environment model may be limited. Harris and Vanderheiden (1980) have summed up the barriers to communication that nonspeaking severely disabled children encounter. They are as Eollows: 
1. Reduced or inconsistent ability to interact with and explore the environment;

2. Reduced or inconsistent ability to play/interact with other persons motorically and vocally and to stimulate vocal feedback from caregivers and others;

3. Inability to express emotions, needs, and thoughts and to exchange information with others in consistent, reliable, and effective manners;

4. Inabllity to develop control of "normal" communication mechanisms (oral speech and fine motor mechanisms) (p. 234).

Bottenberg and Hanks (1986) contended that the disabled child, being restricted in experiences, does not have the same opportunities to learn appropriate social, pragmatic and language skills. This restriction may isolate the child. The child may not be willing to or know how to interact with other children. Furthermore, others may deliberately avoid the child due to these limitations.

Rogers-Warren and Warren (1984) contended that language skills arise out of a children's early social interactions. These early social interactions allow caregivers to teach and encourage the child's communication endeavors. This in turn, helps to motivate the child "to respond not only because of the generally socially reinforcing nature of the relationship, but also because of his or her ability to mediate or affect the behavior of the caregiver" (p.61). Children with severe disabilities, on the other hand, may find it difficult to respond and attend to the environment and caregiver's interactions. Ultimately, the caregiver may 
reduce the amount of communicative interactions with a child limited by disabilities, thus impeding the child's potential interest and competency in communication even further.

The communicative environment of a nonspeaking child with severe disabilities may produce certain influences or considerations that a normally developing child does not encounter. One such consideration is the use of an augmentative communication device. This device, being essential for most social interaction, needs to be accepted and adjusted to by the user as well as the receiver. The other consideration is that of social interaction within the natural environment as mentioned by Rogers-Warren and warren (1984). Basil (1986) completed a study of the social interaction in nonverbal children with severe disabilities using augmentative devices. It was found that:

1. Children's responsivity increases as the success in obtaining contingent communicative responses from parents or teachers increases;

2. A state of learned helplessness and lack of communicative initiation was fostered by the parent's lack of contingent responses and conversation domination (p. 9).

Basil (1986) concluded that as a communication device is introduced, environmental intervention may be warranted. Environmental intervention in the study produced the following consequences:

1. Enhanced understanding of the augmentative device and better conversational patterns displayed; 
2. Understanding and acceptance that the use of communication aids must accomplish the same communicative functions of speech;

3. A positive change in the attitudes and expectancies of both the user and significant others in regard to the advantages of mutual communicative interaction ( $p .11-12$ ).

Additionally, Buzolich (1986) commented that nonverbal children with severe disabilities need the abllity to exert as much control over their environment as possible. These children are "often treated as nonparticipants" (p.14) which can foster learned helplessness and stunt language development. Therefore, this control may be important while the child is beginning to use an augmentative device, especially since language learning can then be facilitated. Morris (1987) stated that "the early emphasis on communication and interaction skills.. develops the communicative competence and a reliable system that will enable the child to use an augmentative communication system" (p. 79).

In considering augmentative or alternative communication systems for any child with disabilities, it is important to understand that many variables determine the effectiveness and competency with which a child can use a system. According to Bottenberg and Hanks (1986), these variables "include the child's cognitive, motor, and sensory status, receptive language skills, the desire to communicate, the specific communication mode used, and the child's attitude towards the communication mode" (p. 212). 
The attitudes and acceptance of those in which the child comes in contact while attempting to use the communication system will also influence the child's feelings toward the system, as well as the child's motivation to become proficient in using the system to foster the potential for communicative competence.

Light, Collier and Parnes (1985a), formulated similar conclusions to those stated above. They reported that the children they followed, being nonspeaking and using augmentative communication devices, were restricted in their conversational input from various barriers presented by their caregivers. During parent and child interactions, the adult dominated the discourse and took the responsibility for topic initiations, carrying the conversation, and filling in silent gaps by repeating and rephrasing their prior statements. The authors stated that it may have been possible that the children, restricted by the physical and cognitive demands as well as the time constraints of their communication devices, found it easier to respond to only the conversational obliges of the caregiver. This would help to explain the asymmetrical nature of the parent/child discourse patterns. It was concluded that this lack of conversational substance, was not beneficial towards learning communicative competence. Thus, the caregivers of nonspeaking children with communication devices need to encourage independence by allowing their children to 
Initiate, expand their utterances, and carry the conversation. It is also suggested that caregivers allow their children the time to express a variety of communicative functions to increase the "control over the channel of information within thelr environment" (Light, collier, and Parnes, 1985b, p. 105).

To this point, it is evident that the communicative environment as well as the communication system plays a significant role on language development and competence with disabled children. We must, however, consider the fact that many of these communication devices display single semantic or vocabulary items that the communication aid user must combine. It is vital then to realize the importance that semantic development has on aided or augmented linguistic competence.

\section{STRATEGIES FOR VOCABULARY SELECTION}

Vocabulary selection for nonspeaking children with severe disabilities is continuously expanding. Guidelines have been suggested; however, nothing has been adopted or supported by empirical evidence.

It is generally decided that the vocabulary items for a child's first words should follow that of normally developing lexical acquisition as well as mold to the special needs of the child (Lahey \& Bloom, 1977; Fristoe \& Lloyd, 1980; Carlson, 1981). Lahey and Bloom (1977) outlined some 
critical areas involved in vocabulary selection. They contend that the contexts for which these words will be learned and used will determine their eligibility for selection. Words that can be used for a variety of items or events "are words that will serve the child more frequently in his effort to communicate and may offer more opportunities for input stimulation" (p. 342). They select words that closely follow the normally developing patterns of relational and substantive words, but that will be functional and of interest to the child. Relational words being those that refer to the relations between objects. Substantive words are those that refer to specific objects or categories. Additionally, words that can be taught and used in many different forms may foster language learning. Lahey and Bloom (1977) suggested that words for an expressive lexicon should be words that represent or can combine to demonstrate particular content categories. These categories are action, entity, attribute, possession, agent, locative, recurrence, object, negation, and demonstrative.

Ottman (1981) stated that the vocabulary items chosen should be of functional use to the child. such items as proper names of familiar persons, "body parts and bodily needs" (p. 4), and emotions or feelings that can be expressed. The inclusion of emotions and feelings is vital to the child's ability to have a sense of control and normalcy. 
The lexicon should be "sensitive to the developmental, environmental, and cultural changes" as well as responsive to the inventive experiences that normally developing children can encounter with language (Carlson, 1981, p. 244). Carlson asserted that the vocabulary items need to be appropriate to the activities and settings in which the child interacts and to the child's level of ability. The words also need to provide the potential for requesting various experlences that the child may have missed.

Light, Collier and Parnes (1985b) stressed the importance of symbols or words indicating communicative functions. The expression of communicative functions encompass the intentions to request, clarify, comment, answer, protest, and acknowledge. For example, a question mark or the word "more" indicating the request for further information. Thus, making nonspeaking children competent communicators by allowing them to exercise more "control over the" flow of "information within their environment" (p. 105$)$.

It has also been suggested that the vocabulary selected be not only functional, but reinforcing and reinforceable (Porter, 1987). A reinforcing vocabulary is one that promotes motivation to communicate by allowing the child the option of preference and freedom to control the expressive lexicon. A reinforceable lexicon is one that allows the communication aid user to receive consequences and have 
control over other's behaviors through the use of the communication system. Porter (1987) continues to specify word categories such as "those reflecting feelings..... pleasure or displeasure, specific items and events, and potentially reinforcing objects and activities" (p.83). As the lexicon is required to expand to continue to meet the user's needs, Porter recommended that expansion should be systematic. She proposed the following strategies be implemented :

1. Observed Need - When new words are identified, they are written down. If the new word occurs twice or more in one week, it is added to the communication device;

2. Systematic Categorization - For ease of visual identification, categories of words are placed on one line;

3. Specificity of Selection - Modifiers should be added to request specific items (p.85).

It is also important to remember that the individuals who interact daily with the disabled child may have many insights to valuable lexicon items that can be useful and rewarding for the child to communicate. Parents, teachers, and siblings are all reliable sources which represent a variety of contexts (Carlson, 1981). These sources may also provide the vocabulary items that the child receptively knows and needs on a dally basis. This will allow the child to learn basic communication and interactions skills without struggling to learn new words, as well as the concepts for those words. 


\section{SUMMARY}

It is apparent that the environment or manner in which twins, and/or children with disabillties are raised can affect language acquisition and competence in ways that normal singleton children may not experience. These differences account for language delays and in some cases a sense of linguistic and social helplessness. Augmentative communication devices assist in providing these children with the means to become proficient communicators in many contexts. The vocabulary selection for the devices become our job as speech and language experts. The literature concerning vocabulary selection for children's augmentative communication devices is limited. Thus, we must rely on the people close to and familiar with a child to provide us with the lexicon that enable a nonspeaking child to communicate. 
CHAPTER III

METHODS

SUBJECTS AND SELECTION PROCEDURES

subjects included three identical and three fraternal twin pairs between the ages of 3.2 and 10.11 years. Their mean age was 7.1 years. The children within each twin pair were of the same sex. Two of the subject pairs were female, four were male. Each twin pair lived within the same household. Table I describes the twin pairs in detail.

TABLE I

SUBJECT STATUS

PHYSICAL STATUS

SUBJECT ACE SEX NONSPEAKING CHILD SPEAKING CHILD TWIN STATUS (in yrs)

1A/1B 3.2 F Nonambulatory Ambulatory Fraternal

2A2B $6.1 M \quad$ Nonambulatory Ambulatory Identical

3A/3B 6.2 F Nonambulatory Ambulatory Identical

4A $4 B \quad 7.8 M \quad$ Nonambulatory Ambulatory Identical

5A 5B 8.7 M Nonambulatory Ambulatory Fraternal

6A6B 10.11 M Nonambulatory Ambulatory Fraternal

One child from each twin pair was able-bodied, speaking and developing normally with respect to cognition, sensorymotor abilities and speech/language as reported by their 
parents, speech-language pathologists and/or educators. The other twin was nonambulatory, nonspeaking and diagnosed by a physician as having cerebral palsy. Nonspeaking was operationally defined as a condition where the individual is unable to use oral speech as the primary mode of communication. Nonambulatory was operationally defined as a condition where the individual is unable to use independent ambulation as the primary mode of mobility.

Cognition status of the disabled child is described by the presence or absence of an AAC system and size of vocabulary within each child's system. Since cognitive assessment is so difficult in this population, no specific cognitive measures or descriptions were required. No criteria for gender, race, or socioeconomic background were imposed because of a restricted subject population. Data were collected across the United States and Canada making strict subject criteria difficult. Table I illustrates whether the nonspeaking twin used an AAC system and how many words were contained in a prlor vocabulary list prepared for that child. 
TABLE II

AAC SYSTEM USE BY DISABLED TWIN

SUBJECT

AGE

1B

2B

$3 B$

$4 B$

5B

6B
3.2 yrs

6.1

6.2

7.8

8.7

10.11
AAC SYSTBM IN USE

No

YES

YES

NO

YES

YES
NO. OF WORDS ON PREPPARED VOCABULARY LIST

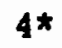

20

50

$44 * \star$

75

700

* denotes words understood, however, no vocabulary list had been prepared.

** denotes words understood, however, no AAC system in use.

Additionally, this study collected data from one other group of subjects, the parent or caregiver of the twin pairs. No subject criteria were placed upon caregivers.

\section{DATA COLLECTION}

The twins were found by sending information letters explaining the proposed research to private clinicians, speech and hearing clinics and various organizations that serve children with disabilities. Families or clinicians interested in participating in the study were sent the following:

1. A cover letter and instructions for parents and clinicians (See Appendix A).

2. An informed consent form (See Appendix B).

3. Two 110-word vocabulary forms (See Appendix C). 
4. An audio-cassette tape.

5. Guidelines for collecting language samples (See Appendix $D$ ).

6. Self-addressed stamped return envelope.

The parent of the twins was asked to complete two 110 word vocabulary lists; one for each of their children. The intention was to acquire 100 words for each child. One hundred ten words were listed to ensure there was no duplication of words (See Appendix E). One of the lists was representative of the vocabulary items that would be needed by the speaking twin if he/she were unable to speak. The second list was comprised of the 110 vocabulary items chosen so that the nonspeaking, disabled child could communicate effectively. Instructions to help caregivers decide which words should be selected for the nonspeaking twin were as follows:

Please list the 110 most important words your child needs in order to communicate effectively during a regular day. Some parents find it easy to think of this 1 ist as the 110 words that their child would use a lot if he/she could talk. Before completing the list, you may find it helpful to observe your child carefully for a while. If a vocabulary list has already been made for your child, you may use the words in that list.

A one hour language sample was also elicited from the speaking, able-bodied twin during a conversation or play activity using Fisher-Price toys, Legos or Play-Doh. This was conducted by the clinician or parent of the nonspeaking twin if the child was located a distance from portland. If 
the child was within driving distance, the language sample was elicited by this researcher.

Confidentiality of the subjects was maintained. Each subject and parent was assigned a number and their vocabulary lists were entered into the data base under these numbers.

\section{DATA ENTRY}

The language samples were transcribed and edited according to predetermined transcription rules (Lee, 1974; Barrie-Blakely, Musselwhite \& Rogister, 1978; and Miller, 1981) (See Appendix $F$ ). The first 50 utterances were deleted to account for the child's unfamiliarity with the task or adult. The subsequent 1000 words were used for analysis. The 1000 words from the one hour language sample along with the 100 words from each of the vocabulary lists were then entered into a computer database system. An IBM 386 microcomputer with a 20 megabyte hard disk was used. The database software chosen was Advanced Revelations, Cosmos Inc. 1989. Data were recorded with a Micro ECM-D8 SONY Electric Condenser Microphone. The data were transcribed using a Sony BM-80 Dictator/Transcriber.

DATA ANALYSIS

Descriptive statistics were used for the data analysis. For the first research question, a composite list of common 
words selected by the parent for each twin pair was created. Words common to both twin lists were extracted. A percentage was obtained of the lexical agreement between the two twin vocabularies and the composite list for each twin pair. The percent agreement was calculated by dividing the number of common words in each parent 1 ist by the total words in the composite 1 ist.

For the second research question, the language sample of the speaking twin was compared to the words selected by the parent for each twin. Percentages of lexical agreement were obtained for common words between each 100-word list selected by the parent and the 1000-word language sample of the normally developing twin. In order to compare lists of different lengths, two calculations were performed.

First, the number of common words between the 1000-word language sample and each of the two 100-word lists was obtained. To determine the percent lexical agreement of the common words with each of the parent lists, the number of common words was divided by 100 . One hundred represents the number of total words in each parent 1 ist.

To determine the percent lexical agreement between the common words and the language sample, a different procedure was used. The number of unique words was obtained for the language sample. Unique words are types that are dissimilar to each other and directly corresponds to the numerator in the type-token ratio (TTR). This method assured that no 
word in the language sample could be counted more than once and thereby influence the resulting percentage. The number of words common to the language sample and parent list was divided by the number of types in the language sample.

For the third research question, a composite list was created consisting of the words common to the language sample of the speaking twin and the parent-selected lists for each twin child. 


\section{CHAPTER IV}

\section{RESULTS AND DISCUSSION}

This study posed and answered three research questions. The first question sought to determine the similarity of the vocabulary selected by the caregiver of a disabled nonspeaking twin and a normally developing twin. The second question examined the similarity between the vocabulary selected by the caregiver of each twin and the words actually spoken by the normally developing twin. The final question identified actual words that were similar between the caregivers' lists for each twin child and the words actually spoken by the normally developing twin. In this chapter, the results of each research question will be presented and discussed.

RESULTS

The first research question posed was: What is the percentage lexical agreement between the parent's vocabulary lists for the speaking and nonspeaking twin? Table III presents these data. It illustrates that parent-selected vocabulary agreement ranged between 438 to 618 . For example, 48 out of 200 words in the composite list for 1A/1B were the same. 4A's and 4B's parents chose 61 words that 
were the same for the speaking and nonspeaking twin. A median of 54.58 and a mode of 488 were computed. The mean agreement was 49.78 with a standard deviation of 6.1 . Therefore, approximately half of the words that were chosen for the speaking child were also chosen for the nonspeaking child.

TABLE III

PERCENT LEXICAL AGREEMENT BETWEEN PARENT LISTS

SUBJECT NO. WORDS IN COMMON PERCDNT AGRERMMENT

$\begin{array}{lll}1 A / 1 B & 48 & 48 \% \\ 2 A / 2 B & 48 & 48 \% \\ 3 A / 3 B & 51 & 51 \% \\ 4 A / 4 B & 61 & 61 \% \\ 5 A / 5 B & 47 & 47 \% \\ 6 A / 6 B & 43 & 43 \%\end{array}$

The number of words in common within each twin pair changes when the ages of the children are considered. A decrease appears to occur around the age of eight years. It seems that the children older than $4 \mathrm{~A} / 4 \mathrm{~B}$ ( 8 years of age) have less words in common than the younger twin pairs.

When the fraternal and identical twin pairs are analyzed separately, additional information is gained. For the fraternal twin pairs $1 A / 1 B, 5 A / 5 B$ and $6 A / 6 B$, the number of common words ranged between 43 to 48 words with a mean of 46 and a standard deviation of 2.2. The identical twin 
pairs $2 A / 2 B, 3 A / 3 B$ and $4 A / 4 B$, demonstrated a higher commonality between words. The number of common words for the identical twin pairs ranged between 48 to 61 words with a mean of 53.3 and a standard deviation of 5.6.

The second research question posed was: What is the percentage of lexical agreement between the language sample of the speaking twin and the parent's vocabulary lists for that child and the nonspeaking twin? A parent-selected 100word vocabulary 1 ist was examined for each child within a twin pair. A corresponding 1000-word language sample was used for comparison. In order to compare the language sample to the individual word lists, the types or unique words were identified in each sample. Table IV presents list sizes and number of unique words in each language sample. For example, there were 241 types in $1 \mathrm{~A}$ 's language sample out of a total 1000 words. A type-token ratio was then computed for each sample based on the 1000 tokens and the number of types. Type-token ratios ranged from .201 to .321 with a mean ratio of .254 . 
TABLE IV

LIST SIZES AND

NUMBER OF UNIQUE WORDS FOR LANQUACE SAMPLE

NO. OF WORDS FOR

INITIALS $\frac{\text { PARENT LIST }}{\text { SA* } \text { LNA }^{\star}}$

IA/1B $\quad 100 \quad 100$

2A/2B $\quad 100 \quad 100$

3A $3 B \quad 100 \quad 100$

4A/4B $\quad 100 \quad 100$

5A 5B $\quad 100 \quad 100$

6A/6B $\quad 100 \quad 100$

* Denotes abbreviations:
NO. OF UNIQUE

WORDS FOR

LANGUAGE SAMPLE

241

.241

235

.235

241

.241

284

.284

.201

201

.321

The percent lexical agreements between each parent 1 ist and the types in each language sample are presented in Table V. Each line of the table represents data for one twin pair. There are four columns for each twin pair. The first two columns contain data for the speaking twin; the second two columns for the nonspeaking twin. Two fractions represent lexical agreement calculations for the speaking twin; two fractions are for the nonspeaking twin. A percentage was calculated for each corresponding fraction. For each child, the numerators in the parent list and language sample columns were identical. They indicated the number of common words between the language sample and the parent-selected word list for that child. For example, for 
1 A there were 38 words in common to the language sample and the parent-selected word list.

TABLE $V$

2-WAY COMPARISONS:

PERCENT LEXICAL ACREBMENT BETWEEN

PARENT LISTS AND LANGUACE SAMPLE

SPEAKING CHILD

SUBJECT PARENT LIST LANG, SAMPLE SURJECT

$1 \mathrm{~A}$

$\frac{38}{100}=388$

$\frac{38}{241}=168$
$\frac{26}{235}=118$

1B

$$
\frac{26}{100}=268
$$

$\frac{44}{241}=188$

$\frac{44}{100}=448$

$\frac{35}{284}=128$

$$
\frac{35}{100}=358
$$

$\frac{25}{201}=128$

$$
\frac{25}{100}=258
$$

$\frac{29}{100}=298$
28

38

$4 B$

$5 B$

NONSPEAKING CHILD

PARENT LIST LANG. SAMPLE

$$
\frac{36}{100}=368 \quad \frac{36}{241}=158
$$$$
\frac{22}{100}=228 \quad \frac{22}{235}=98
$$$$
\frac{31}{100}=318 \quad \frac{31}{241}=138
$$

$\frac{36}{100}=368 \quad \frac{36}{284}=138$

$\frac{26}{100}=268 \quad \frac{26}{201}=138$

$6 \mathrm{~B}$

$\frac{25}{100}=258 \quad \frac{25}{321}=88$

Overall, for the speaking children, the number of common words ranged between 25 to 44 words with a mean of 32.8 and a standard deviation of 7.47 . This means that an average of 33 out of 100 words appeared in the speaking child's parent lists and on the language samples. For the nonspeaking children, the number of common words ranged between 22 to 36 words with a mean of 29.3 and a standard deviation of 5.9. Thus, an average of 29 words appeared in the language samples and on the parent's lists for the 
nonspeaking children.

The demoninator under the parent list columns was always 100 and equaled the number of words in the parentselected word 1 ist. The denominator under the language sample columns equaled the number of unique words or types in the 1000-word language sample. This number varied from child to child. Since the total number of words in each list differs, separate percentages were calculated for each child.

The percentages under the parent list columns represent the lexical agreement between the language samples and the parent lists. For example, 38 out of 100 words for $1 \mathrm{~A}$ in the parent-selected word 1 ist were also in the language sample, so the percentage of lexical agreement between this speaking child and her parents' 1 ist was 388 . For $1 B$, the nonspeaking twin of 1A, 36 out of 100 words in the parentselected word 1 ist also appeared in the language sample. Overall, the percent agreement for the speaking children ranged from $25 \%$ to $44 \%$ with a mean of $32.8 \%$ and a standard deviation of 7.47. These results were similar to those for the nonspeaking children which ranged from 228 to 368 with a mean of 29.38 and a standard deviation of 5.9.

The percentages under the language sample columns represent the lexical agreement between the parent lists and the language samples. For example, 38 words out of 241 types for $1 A$ were also in the parent list for that child. 
Therefore, 16 of the words in the language sample were also in the parent list for that child. For 1B, 36 words out of 241 types were also in the parent 1 ist. Thus, 158 of the words in the language sample were also in the parent list for 1B. Overall, the percent agreement between the speaking children ranged from 98 to 188 with a mean of 138 and a standard deviation of 3.35. These results were similar to those for the nonspeaking children which ranged from 88 to 158 with a mean of $11.8 \%$ and a standard deviation of 1.97 .

Further information is provided when age is considered. The percent agreements between the parent lists and the language samples tend to decline for twin pairs over 8 years of age. This is particularly evident under the parent list columns for the speaking and nonspeaking child. For example, the speaking twins $5 \mathrm{~A}$ and $6 \mathrm{~A}$ hold the percentage agreements of 258 and 298 respectively. These percentages are lower than the percentages for the younger children, who have agreement scores of $388,268,448$ and 258 respectively. This is also evident for the nonspeaking twins $5 \mathrm{~B}$ and $6 \mathrm{~B}$.

The third research question posed was: What vocabulary items constitute a composite vocabulary list of common words selected by the parents for each twin and spoken by the normally developing twin? For each twin pair 1200 words (1000 tokens from the language sample and 100 words each from the two parent-selected 1 ists) were compared for commonality. The common words were extracted to create the 
composite list of vocabulary items. Composite lists for each twin pair are 1 isted in Table VI. The composite 1 ists ranged from 13 to 27 words in common, with a median of 20 words and a mode of 24 . The mean number of words in common for each composite 1 ist was 20 with a standard deviation of 5.7 words. In other words, approximately 20 common words were chosen by the parents for each child and spoken by the normally developing twin.

\section{TABLE VI}

3-WAY COMPARI SONS :

COMPOSITE VOCABULARY LIST FOR EACH TWIN PAIR

\begin{tabular}{|c|c|c|c|c|c|c|}
\hline SUBJECT: & $1 \mathrm{~A} / 1 \mathrm{~B}$ & $2 A / 2 B$ & $3 A / 3 B$ & $4 A / 4 B$ & $5 \mathrm{NAB}$ & $6 \mathrm{AN} 6 \mathrm{~B}$ \\
\hline & BED & BED & BREAKFAST & BATHROOM & GET & BOOK \\
\hline & CAR & DAD & DAD & CAR & $\infty$ & CLOTHES \\
\hline & DAD & DOWNSTAIRS & DINNER & DAD & I & $\infty$ AT \\
\hline & $\infty$ & $\infty$ & DO & DOWN & IN & FRIEND \\
\hline & COOD & GRANDMA & DRINK & GIRL & MAKE & I \\
\hline & HOUSE & $\mathrm{ME}$ & ENOUGH & $\infty$ & MORE & MOVIE \\
\hline & & MOM & GET & HETP & No & PLAY \\
\hline & ME & No & HETP & HOT & OUT & POP \\
\hline & MILK & ON & HOW & IN & OVER & POPCORN \\
\hline & $\mathrm{MOM}$ & OUTSIDE & ЛICE & ME & $\{S\}$ & RIDE \\
\hline & MORE & $\{S\}$ & LIKE & MOM & SEE & $\{S\}$ \\
\hline & MY & SISTER & LUNCH & OFF & TAKE & TV \\
\hline & NEED & SIT & $\mathbf{M E}$ & ON & WANT & WATCH \\
\hline & No & STAND & MOM & OUT & WHERE & \\
\hline & OFF & UPSTAIRS & MORE & OVER & YES & \\
\hline & ON & WALK & $M Y$ & RUN & & \\
\hline & PLAY & YES & $N \cdot T$ & $\{S\}$ & & \\
\hline & $\{S\}$ & & NEED & STOP & & \\
\hline & TIRED & & No & TEACFER & & \\
\hline & TV & & PLAYY & TIME & & \\
\hline & UP & & $\{S\}$ & UP & & \\
\hline & WALK & & TAKE & YES & & \\
\hline & WANT & & WANT & YOU & & \\
\hline & YES & & WHERE & RACAIEL & & \\
\hline & & & WHY & & & \\
\hline & & & YES & & & \\
\hline TOTAL & & & YOU & & & \\
\hline COMMON ix & 5 : 24 & 17 & 27 & 24 & 15 & 13 \\
\hline
\end{tabular}




\section{DISCUSSION}

This research suggests that parents raising twins, one being normally developing and the other presenting a nonambulatory, nonspeaking status, do indeed determine differences in expressive vocabulary for the two children. This seems to occur even though the children live in similar verbal environments. Interpretation of the results will be presented in the following pages.

The first research question examined the percentage lexical agreement between the parents' vocabulary lists for the speaking and nonspeaking twin. It is interesting that on the average, about 508 of the words selected for the speaking child were also selected for the nonspeaking child. If a lower percentage had been obtained, one could argue that the parents were selecting vocabulary items for the nonspeaking twin that were significantly different than that of the speaking twin. If a higher percentage had been obtained, the parents may not have identified certain vocabulary items that were uniquely appropriate to the nonspeaking child's lifestyle. Neither a high nor a low percentage was obtained, therefore, another interpretation must be offered. Since an average of 49.78 was obtained, it is possible that the vocabulary lists reflect equally the vocabulary of the normally developing child and the nonspeaking, disabled child. The parents seemed to sense the 
different needs of the nonambulatory, nonspeaking child and compensate for those needs by choosing certain words for the vocabulary list they feel are necessary for that child's lifestyle. Best (1988) supports this finding by suggesting that parents of twins react to individual differences in their children and then form their language to meet the needs of each child. She states that there is variability in the language of twins even though the environment is held constant. The linguistic input provided by parents varies depending on the characteristics and Iinguistic and cognitive abilities of each child (Cross, 1977; Best, 1988). This research concurs that when raising one normally developing twin and one nonspeaking, nonambulatory twin, parents recognize the influences of both physical and communicative situations upon expressive vocabulary acquisition. They select words that best meet the needs of each child. These parents, however, did allow many normally acquired words to be represented on the vocabulary list as reflected in the fact that approximately half of the words chosen for the nonspeaking child were also chosen for the speaking child.

Additionally, the results have shown that the identical twin pairs had a higher mean percentage of words (53.38) in common than did the fraternal twin pairs (46\%). Munsinger and Douglass (1976) support this finding by stating that identical twin pairs' language skills are significantly more 
similar than that of fraternal twins.

The second research question examined the percentage lexical agreement between the language sample of the speaking twin and the parent's vocabulary lists. Looking at the low percent agreements in Table $V$, between the language samples and the parent-selected lists for each child, it would seem that the words spoken by the normally developing twin are not chosen by parents for either of the children. On the contrary, it seems that the parents did choose words within a normally developing lexicon. It is speculated that the parents chose words that were necessary for daily needs and rituals rather than words of play that likely occurred during the language sample. Additionally, one must remember that functor words (the, at, a, etc.) may comprise much of the language sample yet very little of the parent-selected lists, and is therefore another likely reason for the low percentage agreements.

In comparing columns \# 1 and 3 of rable $v$, the percent agreements for the speaking child/parent list as compared to the nonspeaking child/parent list, however, are very similar. As mentioned in the discussion of question 1 , the parents chose 508 of the same words for each child regardless of physical condition. In support of this, it seems that mothers of twins often interact with the twins as one unit instead of interacting with each on an individual basis (Stafford, 1987). Tomasello, Mannle and Kruger (1986) 
also state that the mothers of twins direct their language towards both children rather than directing their interactions individually. These types of linguistic interactions may limit the characteristic and unique lexical items chosen for each twin, thus encouraging the parent to select many of the same words for each child.

In comparing columns $\$ 2$ and 4 of Table $V$, other interesting results are presented. In general, the percent agreements were slightly lower for the nonspeaking child/language sample comparisons than for the speaking child/language sample comparisons. These results were apparent in four of the six twin pairs. This represents the possibility that fewer words on the parent-selected vocabulary list for the nonspeaking child were present in the speaking child's language sample. This may be a reflection of the very different needs of the nonspeaking, nonambulatory child that may not be common in the language of a normally developing child. Yoder, Farran, and Allen (1984) state that mothers of a twin with disabilities may spend less time in joint attention and responsive behaviors with that child than with the normal twin. This observation may contribute to the lower percentage agreement of the parent's vocabulary list for the nonspeaking child/language sample comparisons than of the speaking child/language sample comparisons. These slight differences, however, may be due to chance. Larger sample sizes would be needed to 
verify these differences.

Many additional reasons support the lower percentage agreements for the nonspeaking child. Harris and Vanderheiden (1980) state that the disabled child has a "reduced ability to explore his/her environment, to play and interact with others, and to express emotions and needs" (p. 234). This in turn may diminish verbal interactions from parents or caregivers. Children with disabilities may then become less interested in communicative interactions (Rogers-Warren \& Warren, 1984). The parent doesn't have the privilege of hearing words that the child might speak. Therefore, interactions with that child to strengthen and encourage words that are useful and reinforcing are diminished. This type of scenario may increase the possibility of the parent selecting words less common to the language sample of the speaking child.

The parent-selected vocabulary 1 ist for the speaking child had more in common with the language sample for that child. For the speaking child, the parent needs only to listen to that child in various communicative activities to be aware of the specific words that are useful and reinforcing for that child. Therefore, selecting words for the speaking child may be a simpler task since the words are significantly more conspicuous, yet narrowing them to a 1 ist of 100 may be more difficult.

The third question looks at the vocabulary items that 
constitute a composite word list for each twin pair from the parent-selected word $l$ ists and the language sample of the speaking twin. These composite vocabulary lists represent not only normal vocabulary acquisition, but also the unique vocabulary items that children with disabilities may frequently encounter.

If one looks between the composite lists for each twin pair, certain words reappear often. The plural morpheme \{S\} occurs in a11 six of the composite lists. The word YES occurs in five of the six and the words MOM, NO, GO, ME, and DAD occur in four of the six lists. These words may be particularly significant for use on communication devices since they occur across age ranges with consistency in both language samples and parent-selected vocabulary 1 ists.

These words have been duplicated in reports on vocabulary development. Nelson (1973) studied initial expressive 50-word vocabularies in children. She noted that the words $M O M(M Y)$ and $D A D(D Y)$ were among the most common first 10 words for her subjects. The above remaining common words of the twin pairs (\{S\}, YES, NO, GO, ME) were also present in various initial 50-word vocabularies presented in Nelson's research.

A study by More (1990), examined the frequency of lexical items chosen for fifteen 3 to 6 year old nonspeaking disabled children. She states that the words MOM and DAD were present in 29 of the 30 subject 1 ists. The words Go 
and \{ 9$\}$ were present in 28 lists, NO and YES present in 20 lists, and ME present in 14 of the subject lists. Thus, More's study lends further validity to the words common between the twin pairs.

Lahey and Bloom (1977) suggested that an expressive lexicon should encompass various content categories: entity, attribute possession, locative, recurrence, object, negation, demonstrative and agent. Each of these content categories is represented in the six composite lists. For example, GOOD represents the category attribute, MY represents the category possession, N'T represents the category negation. Lexical items illustrating these categories should be available to able-bodied and disabled children in the same verbal environment. This is confirmed strongly since the categories were chosen by the parents and spoken by the children in this research project.

Light, Collier and Parnes (1985b) stressed the importance of words representing the communicative functions such as requesting, clarifying, commenting, answering, protesting and acknowledging. Again, words are present in the composite lists to engage these interactions. For example, WANT functions as a request, NO functions as a protest, and ON can function as a answer. Words representing communicative functions, allow the child to have some personal control over interactions. The child is able to exploit the functions of language to explore and discover 
him or herself and the interactive world.

The number of words in common for the language samples and the parent lists show no consistent pattern; however, the two eldest twin pairs age 8.7 and 10.11 seem to show a decline in the number of common words with age. This may reflect different personalities as children grow and separate according to their own needs and personalities. older children may have access to a wider and more varied environment that carries with it greater demands and expectations in verbal skills. Thus, the able-bodied child within the older twin pairs may be experiencing comparatively different verbal environments than that of the disabled twin. This result also demonstrates that vocabulary size for older children is larger, making commonalities occur with less frequency since there are more words to choose from. Owens (1988) supports this argument by discussing lexical acquisition. It seems that vocabulary growth is rapid up to the age of six years. Between the ages of 7 and 11 years, however, a child further increases his/her lexicon by developing multiple meanings, semantic classes, logical concepts, synonyms, antonyms and other vocabulary interrelationships.

Clearly, the common words reflect those that are characteristic to both twins rather than those that may be necessary for each individual child. For example, such words as HELP, BATHROOM and WANT are on one or more of the 
composite lists and are useful for each of the twins. Words such as WHEELCHAIR and WET did not make it to the 1 ist of common words since they are unique or more common to the nonspeaking twin and are unlikely to show up in the language samples or on the parent 1 ist for the speaking twin. 


\section{CHAPTER $V$}

\section{SUMMARY AND IMPLICATIONS}

\section{SUMMARY}

Children with severe physical disabilities often do not have the capabilities for oral communication. Therefore, the vocabulary needs of nonspeaking children has been a subject of research in the area of augmentative communication for a number of years. The idea of allowing children with disabilities the opportunity for expression and communication is one not easily ignored. Obtaining vocabulary items, however, that are useful to nonspeaking disabled children that also meet normal language acquisition standards has been a concern. This study specifically addresses this concern by looking into the vocabulary issues of twins. The purpose of this research project is to verify that differences exist in the expressive vocabulary needs that are determined for a nonspeaking, cerebral-palsied twin and a speaking, able-bodied twin by a caregiver despite similar verbal environments.

six twin pairs were used. One of the twins in each pair was normally developing in respect to cognition, sensory abilities and speech/language. The other twin had both a nonambulatory and nonspeaking condition. Their ages 
range between $3 ; 2$ and $10 ; 11$ years with four male twin pairs and two female twin pairs. The procedures included a 110word parent-selected vocabulary list for each twin which was to be representative of the words each child requires to communicate effectively. Additionally a 1000-word language sample of the speaking twin within each twin pair was obtained during a play activity. The vocabulary items obtained were then compared to answer the following questions: 1) What is the percentage lexical agreement between the parents' vocabulary lists for the speaking and nonspeaking twin?; 2) What is the percentage of lexical agreement between the language sample of the speaking twin and the parents' vocabulary lists for that child and the nonspeaking twin?; 3) What words constitute a composite vocabulary $l$ ist of common words selected by the parents for each twin and the words actually spoken by the normal twin? Results indicate that 508 of the words chosen by the parent for the nonspeaking twin were also chosen for the speaking twin. This split percentage suggests that parents indeed address normal language acquisition, while not ignoring the unique words necessary to meet the needs of their disabled child. Low percentages were obtained when the words in the parent-selected lists for each child and the language samples were compared. The words chosen for the nonspeaking twins, however, presented slightly lower percentage agreements to the language sample than the 
speaking twins. The lower agreement of vocabulary items reflects the different lexical items needed for the nonspeaking, nonambulatory child that may not occur in the language sample of a normally developing child during a play activity. Therefore, this research project demonstrates that despite similar verbal environments, the words chosen for twins varies with the abilities and needs of each child, as well as other situational influences.

The lexical items comprising the twin composite vocabulary lists satisfy the various areas for semantic content categories and communicative functions. Furthermore, these words seem to be especially relevant since they not only represent words from normal language acquisition, but also meet the needs of nonspeaking physically disabled children.

\section{CLINICAL IMPLICATIONS}

This research contributes to the efforts of those in the process of generating specific word lists and supportable guidelines for vocabulary selection of augmentative communication devices being utilized by children. The vocabulary items generated from this research give some amount of insight into the communicative considerations and needs of the nonspeaking, physically disabled child in a same verbal environment as speaking, able-bodied children. This research project demonstrates that despite similar 
verbal environments, the words chosen for twins varies with the abilities and needs of each child, as well as other situational influences. Parents seem to be sensitive to the linguistic and physical requirements of their children and compensate through the lexical items selected for each child. Thus, when requesting parents or caregivers to select lexical items for the communication devices of their nonspeaking child, it is likely that they will choose appropriate words to meet that child's various communicative needs.

Furthermore, many of the words selected by parents of nondisabled children can be useful and beneficial for nonspeaking, disabled children. This was confirmed by the lexical items chosen for each twin. Many of the words selected for the normal twin were the same as those selected for the nonspeaking twin, thus supporting the contention that words within a normally developing lexicon will be represented. These words also reflected daily needs and routines.

Research such as this may allow children with disabilities to realize their own potential to become effective communicators. This goal can only be accomplished when the lexical items placed on an augmentative communication device are ones that meet the individual needs of the child, are reinforcing, and allow him/her to experience life as a "participant", not an observer. Lexical items should 
facilitate the interactive desires and intents of the child, as well as aid in the recognition of being a capable, intelligent human being.

It is evident that the parents of children can be reliable sources for the word selection of their child's communication device. In this case, parents were able to choose those words that were necessary for their nonspeaking child with disabilities, as well as words that occur in the language of their normal speaking child. This may be an indicator that when selecting the lexical items for communication devices, parents and professionals may want to consider not only lexical items that are characteristic to that child, but also those of same-aged normally developing children and of children within the same verbal environment. In this effort, a disabled child may communicate ideas that are necessary for his/her daily needs along with ideas and intentions similar to every other normally developing child.

\section{RESEARCH IMPLICATIONS}

The next logical step to this study may be to compare the composite lists created in research question \#3 to preexisting vocabulary reports and instruments involving children within the same age range as the twin pairs. For example the vocabulary lists presented by Holland (1975), Rescorla (1989), and Beukelman, Jones and Rowan (1989) may be used for this task. A final composite vocabulary list 
could be created of the words that appear on the twin pair composites, as well as on the pre-existing vocabulary 1 ists. This list would not only represent words from the language sample and those chosen by the parents for speaking and nonspeaking children in similar verbal environments, but those that are present on established and clinically useful vocabulary lists. These lexical items would also be representative across age ranges since it would account the words from each twin pair, ages 3.2 to 10.11 years. Comparing these composite 1 ist words to pre-established vocabulary lists or instruments for children within the twins' age range, lends further validity and relevance. The words contained within each list would meet specific guidelines previously stated and demonstrate further validity by their presence on other vocabulary list reports and language instruments.

Comparing the semantic classes present in the parentselected vocabulary 1 ist for the speaking and nonspeaking twin is also an important research consideration. It may be considered whether the words chosen for the nonspeaking disabled twin represent medical needs, toileting, or limited physical activities. On the other hand, it may be found that the words chosen for the speaking able-bodied twin represent play and physical activities. Fried-oken (1989) proposes that differences in the physical abilities of speaking and nonspeaking children may have a considerable 
influence on the types of lexical items acquired, as well as the 1 inguistic input offered by parents and caregivers. Information such as this would lend further assistance into the distinctive lexical items needed for disabled children, in addition to the words exemplifying normally developing language acquisition.

A further consideration may be to limit the context for which the lexical items would be chosen. This research was not limited to one or two communicative situations. Many interactive contexts may have been represented in the parent-selected word lists, as well as the language samples. Therefore, to produce fully developed and extensive word lists, research must be done in which separate communicative environments (dinner time, getting ready for bed, and getting dressed, etc.) are analyzed. This would allow persons choosing the vocabulary items for communicative aid devices to have an immense supply of words upon which to choose from for specific communicative situations. 
REFERENCES

Ainslie, R.C. (1985). The psychology of twinship. University of Nebraska Press.

Barrie-Blakely, S., Musselwhite, C.R., \& Rogister S.H. (1978). Clinical Lanquage Sampling: A Handbook for students and Clinicians. Danville, IL: The Interstate Printers and Publishers, Inc.

Basil, C. (1986). Social interaction and learned helplessness in non-vocal severely handicapped children. Manuscript submitted for publication.

Best, L. (1988). The linguistic environment of twins: Literature review and lanquage analysis. (Report No. FL017723). (ERIC Document Reproduction Service No. Ed 3039951 .

Beukelman, D.R., Jones, R.S., \& Rowan, M. (1989). Frequency of word usage by nondisabled peers in integrated preschool classrooms. Augmentative and Alternative Communication, $5,4,243-248$.

Bottenberg, D. \& Hanks, J. (1986). Language and speech of physically handicapped children. In Reed, V.A. (Ed.), An Introduction to Children with Lanquage Disorders (pp. 201-219). New York, NY: Macmillan Publishing Co.

Buzolich, M.J. (1986). Cognitive and communicative development in severely physically handicapped nonspeaking children. Paper presented at the International Conference on Augmentative and Alternative Communication, Cardiff, Wales.

Carlson, F. (1981). A format for selecting vocabulary for the nonspeaking child. Lanquage, speech and Hearing Services in Schools, $12,4,240-245$.

Crismore, A. (1982). An investigation of exceptional twins. (Report No. EC151676). University of Illinois. (ERIC Document Reproduction Service No. ED 228818 ).

Cross, T.G. (1977). Mother's speech adjustments: The contributions of selected child listener variables. In Snow, C.E. \& Ferguson, C.A. (Eds.), Talking to Children (pp. 151-188). Cambridge University Press. 
Davis, E.A. (1937). The development of linquistic skill in twins, singletons with siblings, and only children from age five to ten years. Minneapolis, MN: The University of Minnesota Press.

Day, E.J. (1932). The development of language in twins. Child Development, 3, 3, 179-199.

Fried-Oken, M. (1989). Vocabulary selection for the communication prostheses of nonspeaking children with cerebral palsy. March of Dimes Grant Proposal. Portland, OR: Good Samaritan Hospital and Medical Center.

Fristoe, M., \& Lloyd, L. (1980). Planning an initial expressive sign lexicon for persons with severe communication impairment. Journal of Speech and Hearing Disorders, 45, 2, 170-180.

Harris, D. \& Vanderheiden, G.C. (1980). Enhancing the development of communicative interaction. In Richard $L$. Schiefelbusch (Ed.), Nonspeech Lanquage and Communication, (pp. 229-301). Baltimore, MD: University Park Press.

Holland, A.L. (1975). Language therapy for children: Some thoughts on context and content. Journal of Speech and Hearing Disorders, XL, 514-523.

Koch, H.L. (1966). Twins and twin relations. The University of Chicago Press.

Lahey, M. \& Bloom, L. (1977). Planning a first lexicon: Which words to teach first. Journal of Speech and Hearing Disorders, 42,3,340-349.

Lee, L. (1974). Developmental Lanquage Analysis. Evanston, IL: Northwestern University Press.

Light, J., Collier, B. \&arnes, P. (1985a). Communicative interaction between young nonspeaking physically disabled children and their primary caregivers: part 1 - Discourse Patterns. Augmentative and Alternative Communication, $1,2,74-83$.

Light, J., Collier, B. \& Parnes, P. (1985b). Communicative interaction between young nonspeaking physically disabled children and their primary caregivers: Part I - Communicative function. Augmentative and Alternative Communication, $1,3,98-107$. 
Luria, A.R. \& Yudovich, E.I. (1959). Speech and the development of mental processes in the child. London: staples press.

Lucas, E.V. (1980). Semantic and pragmatic language disorders. Rockville, MD: Aspen Publications Corp.

Lytton, H., Conway, D., \& Sauve, R. (1977). The impact of twinship on parent-child interaction. Journal of Personality and Social Psychology, 35, 97-107.

Malmstrom, P.M. \& Silva, M.N. (1986). Twin talk: Manifestations of twin status in the speech of toddlers. Journal of Child Language, 13, 293-304.

Miller, J.F. (1981). Assessing Language Production in Children. Austin, TX: Pro-ed, Inc.

More, L.M. (1990). The Creation of a Core Vocabulary for Initial Lexicon Selection for Nonspeaking Preschool Children. Unpublished master's thesis, Portland state University, Portland, OR.

Morris, S.E. (1987). Therapy for the child with cerebral palsy: Interacting Frameworks. Seminars in Speech and Language, $\underline{8}, 1,71-86$.

Munsinger, H. \& Douglass, A. (1976). The syntactic abilities of identical twins, fraternal twins, and their siblings. Child Development, 47, 40-50.

Nelson, K. (1973). Structure and strategy in learning to talk. Monographs of the society for Research in Child Development, 38, 1-2, 1-137.

ottman, R.A. (1981). The use of communication boards with cerebral palsied non-speaking children. (Report No. E(133530). New York, NY: Old Dominion University, Department of Educational Foundations and Special Programs. (ERIC Document Reproduction Service No. ED 2049591 .

Owens, R.E. (1986). Communication, language, and speech. In Shames, G.H. Wiig, E.H. (Eds.), Human Communication Disorders (pp. 27-79). Columbus, OH: Charles E. Merrill Publishing Co.

Owens, R.E. (1988). Language Development. Columbus, $\mathrm{OH}$ : Merrill Publishing Co. 
Penn, C. \& Haden, R. (1985). The twin situation and its effects on syntax and interactional language over time. British Journal of Disorders of Communication, 20 19 -29 .

Porter, P.B. (1987). Augmentative Communication: Selection of an initial vocabulary. Physical and occupational Therapy in Pediatrics, 7, 2, p. 79-90.

Rogers-Warren, A.K. \& Warren, S.F. (1984). The social basis of language and communication in severely handicapped preschoolers. Topics in Early Childhood special Education, 4, 2, 57-72.

Rescorla, L. (1989). The language development survey: A screening tool for delayed language in toddlers. Journal of Speech and Hearing Disorders, 54, 587-599.

Savic, S. (1980). How twins learn to talk: A study of the speech development of twins from 1 to 3 . London: Academic Press.

Shames, G.H. \& Wiig, E.H. (1986). Glossary. In G. Shames \& E. Wiig (Eds.), Human Communication Disorders, (pp. 613-624). Columbus, OH: Charles E. Merrill Publishing Co.

stafford, L. (1987). Maternal input to twin and singleton children. Human Communication Research, 13, 4, 429-462.

Tomasel1o, M., Michael, $S_{.}, \&$ Kruger, A. (1986). Linguistic environment of 1 to 2 year old twins. Developmental Psychology, 22, 169-176.

Vandell, D., Owen, M., Wilson, K. \& Henderson, V.K. (1988). Social development in infant twins: Peer and motherchild relationships. Child Development, 59, 168-177.

Vanderheiden, G. \& Lloyd, L. (1986). Communication systems and their components. In S. Blackstone (Ed.), Augmentative communication an introduction, (pp. 49161). Maryland: ASHA.

Yoder, P., Farran, D. \& Allen, C. (1984). Mother-infant engagements in dyads with handicapped and nonhand i capped infants: A pilot study. (Report No. EC170802). Chapel Hill: North Carolina University. (ERIC Document Reproduction Service No. ED 249701 ). 
APPENDIX A

PARENT AND CLINICIAN COVER LETTER 


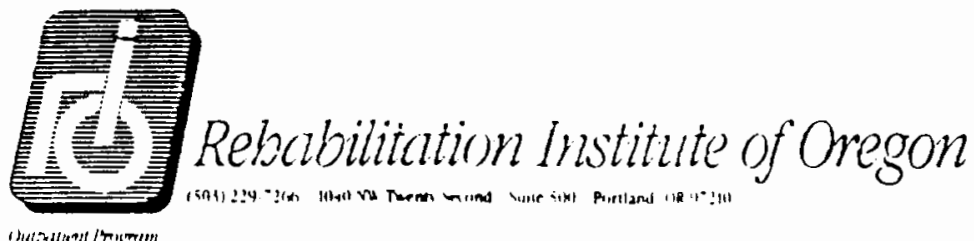

Dear Parents:

I an a researcher and a speech-languace pathologist at Good Samaritan Hospital in Portland. Oregon where I help people who are not able to talk due to physical disabilities. Specifically. I make communication boards for children with cerebral palsy who cannot speak. The parents, teachers, therapists, and I choose words and pictures that go on the boards. and then teach the children to point to the items they want to say.

I am looking for sets of twins. Where one child is nonspeaking and nonambulatory, and thei= twin is develooing within normal inits. I will ask ther to participate in a simple research project. The project will improve the ways that we choose the vocabulary for the communication boards. I invite you and your children to be part of our project. You can help other parents comaunicate with their nonspeaking children, and improve the educstion and language learning of children with severe physical disabilities.

Your participation in the study will take about 2 hours at home. We simply ask you to complete the following instruetions:

1. Read and sign the enclosed latorned consent Form. Inis peraission slip describes the research project poro and tells you about your parental rights for research participation.

2. Fill out a vocabulary list for each twin.

For rour speaking child, make a list of the 110 most important words that your child would need it he/ste could not speak and was using compunication board. All you need to do is to listen to the words that your child uses for day or so, and then make a list of the most comon words.

For the norspeaking child. We ask you to fill out a list of 110 words that your child would use is he/she could talk. Acain. consider all of their daily activities, needs, routines and write down the 110 words that would be needed most.

I rand Sararion

3. Hospual \& Hedical Center 
3. We ask your peraission to have your speaking child participate in this study. We need an audio-tape of your chill talking while he/she plays. This one-hour tape of speech is calied a -language sasple." Either your speech-language pathologist will tape the child, or we will ask you to maxe a tape of your child playing with you. If you are doing the taping. we have included "language sampling instructions" to make the task easy. By taping what the children say, we can see what comon words are chosen by children. Then we can compare what words you chose with the words that your child actualiy used.

When those 3 tasks are completed. you are finished. He want to thank you, in advance, for participating! If you have any questions. please contact we collect at (503) $229-7260$ or ask youz cooperating speech pathologist for assistance. If you are going to prepare the language tafe. Dlease ask your clinician for guidance.

I look fordard to assigting nonspeaking children with cerebral palsy and their families communicate better through your help. Thanks again.

sincerely.

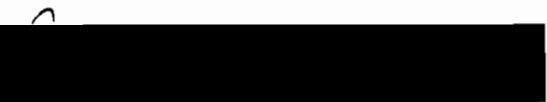

Melanie Fried-Oken, Ph.D.

Clinical Researcher/Coordinator

Augmentative Comunication Service 


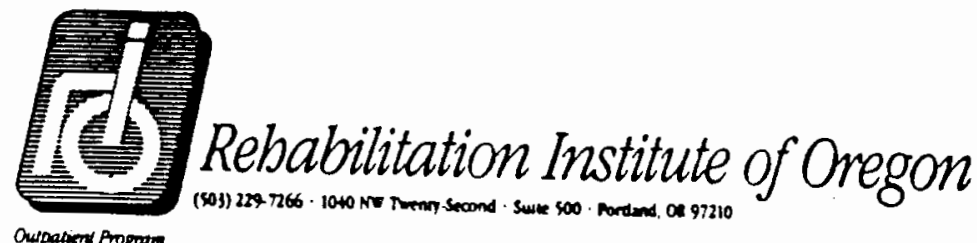

Oupadiere Program

Dear Cooperating Clinicien:

Thank you for agreaing to participate in our twin study. As you know, we ere trying to develop vocabulary guideines for nonspeaking, nonambulatory childran who zely on $\lambda C$ er expresalon. By using the words selected for twins, we will be able to hold the variable of "environmental influence" constant when we examine word ehotces for speaking and nonspeaking ehildrea.

We ask you to help us with the following procedura:

1. Identify aet of twing where ore child is nonopeaking and the other child is developiag withid normal lifits for his/her chronological age.

2. Contact the parants/caregivars, explain the study, and ask the if theg are interested in participating.

3. Send the parerts:

1) Letter to parents

2) Informed consent Form

3) Vocabulary list for the nonspaking child.

4) Vocabulary list for the speaking chfld.

4. We need an audio-taped language sample elicited trom the speaking child. We wil enter 1000 words produced by the child lnto our data base. Fron our recent experience of transcribing 30 cyildren between the ages of 3 to 6 years, we have sound that 60 to 90 minutes of apontaneous apeech produces a lanouage corpus that contains at loset 1000 intelligible. transcribe-able words. since this is a rather lengthy process. we often elicited lenguge in two seasions with the younger chlidren.

We bave included language sampling suggestions for you in this malilog. We exk rou to use your professional judgement and langrage rapilag experienco to help us with data collection. It 1. difficult to ask cooperating cliniciens to collect lenguege samplea tor us aince ther will be non-standard elicitation styles used. Givea our ilmited ubject pool in the portland area howerar, your lenguage sample is the best way to collect data.

T. Cood Samarian

Hospital \& Medial Center 
If the twins do not live in your geographical area, and it is not possible for you to tape the apeaking child. please ask the pareat to elicit the language sample. In that case. please send the parent the cassette tape, malling envelope. Ianguage anpling instructions and information form. The parents might need some cuidance in the language sampling task. We hope that you could offer assistance if needed.

Please mail (or have the parents mail) the completed audiocassette and language sampling information torm to Dr. Melanie Eried-oken in the enclosed cassette mailer.

If you have any questions, please call Dr. Eried-oken at 503-2297266. Thank you again for your time, cooperation, energy and concera. He will be happy to share our results with you as soon as all the data are collected and analyzed.

sincerely.

Melanie Eried-oken, Pb.D.

CIirical Researcher/Coordinator

Augmentative Conunication Service 
APPENDIX B

INFORMED CONSENT FORM 


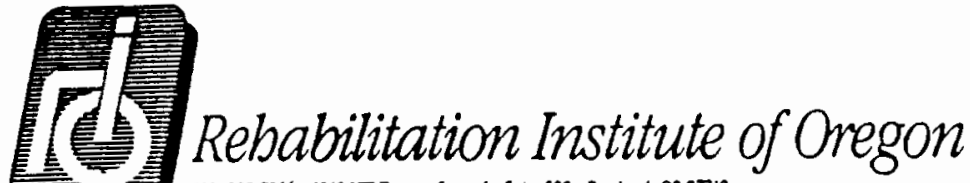

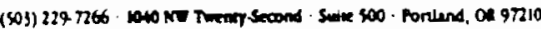

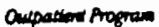

\section{IMFORMED CONSENT FORH}

VOCABULARY NEEDS OF THE NONSPEAKING CHILD AS DETERMINED BY CAREGIVERS

PRINCIPAL INVESTICATOR: MELANIE FRIED-OKEN, Ph.D.

\section{PESCRIPTION OF STUDY}

Some children who have cerebral pelsy canoot control their oral muscles to spak elcectively. They must use comunication alds to express thetr thoughts and needs. Many children point to plctures on communication bonds and books. Otbers use electronlc dertces, such as speak in spell or Apple computers, that opeak lor person. These alds are referred to as augmentatio communtcation gystems.

Every augmentative communication system mus present rords or pletures to chlldren so that thej can choose wat they want to say. For example. a cbild must be cble to point to printed rords or a picture of les crean when asked. "What do you want for dessert?".

The task of selecting the words to put on a communfetion boerd for a nonspeaking chtid 13 a very difficult one. Farents, family members. teachers and thorapists must decide what words and seatences the nonspeaking child might want (or need) to say. The vocabulary must give the child as much comunication freedom as posasble.

Onfortunately, most compunication boards only contaln between 4 and 400 words. Since you can't put every word of a language on a comunfeation aid, most vocabulary lists are restrictive. $\lambda$ nonspeaking chtld cannot say evergthing bo or whe wanta to. The problem facing etults who make comuntcation aids for nonspeaking children 1s: "What words ahould I chooser".

The purpose of this study is to compere vocabulary liets thet are chosen for speaking and nonspeaking children between the coes of 3 to 6 years old. The words that are commoniy melected for all children will be shared with adults who make communication alda.

I. Cood Samaritan

I Hospoal \& Metical Center 
PROCEDURE

Participation in this study will involve bout one hour of your time which can be in your chosen location. You will simply be asked to make two lists of 110 words each: one list of words that rour seaklag child would use to communicate it he or she could not speak: and one list of vords that your ponspeaking child would use 12 he or be could talk.

Your speaking roungster w1ll partlcipete in the atudy, as well. They will be audio-tape recorded for about one hour while they are playing with toy and talking. The children will also take language test to fudge that they understand language within normal age ilnits. The tapes will be transcribed later so that we can see what words the chlidren chose to spek.

To ensure confidentiality, your neme will not be used in this study. Initials will replace the children's names so thet their identities remain private.

\section{DESCRIPTION OF RISKS AND BENEFITS}

There are no algaifleant risks essocieted with this study. You and your child can top anytime you feel uncomlortable during the task. Ho spocific benellts will be derived by participants in this tudy other than supplying common word lists to nonspeaking chlldren. The results w11l help spech-lenguege pethologists and adulta who make comunication lds velect the least restrictive and most uselul vocabulery for augmentative commulcation.

\section{CONSENT}

I have raed this consent form and have discussed with Dr. FriedOken or her representative the procedures described above. I have been given the opportunity to ask questions, which bave been answered to my atisfection. I understand that I can telephone Dr. Frlod-oken, collect, at (503) $229-7266$ to enswer any questions I st111 might have.

I understand that as participant in this acudy my 1dentity and my child: 1dentity, records and data relating to this reaearch study will be kept confldentiel.

It 1s not the pollcy of Good samaritan Honptal and Medical Center. or any other agency funding the research profect in which I an participating, to companate or provide medical treatments in the ovent the research reaults in phyleal lajury. I hould further underatand that ahould I suffer any injury from the research project, compensetion will be avallable only if I establish that the injury occurred through the lault of cood Samaritan Hospltal. its officers or employees or my physician. Further information regarding this pollcy may be obtained from the Office of Research Administration at (503) 229-7218. 
I understand I am tree to refuge to participate in this study at any time or to withdraw erom participation in this study at any time and it will in no way affect my relationship with, or treacment at. Cood Samariten Hospital and Medical Center.

I have read and understood the foregoing:

DATE
Please print childzen's neme:
Children's dete of birth:
Childzen's day care or school:
Please circle one: My children are fraternal identical iwins.

If you experience. problems that are the result of your participation in this study, please contact the Chalr of the Human subjects Research Review Committee, Office of Grants and Contracts. 303 Cramer Hall. Portland state Unlversity. (503) 725-3417. 
APPENDIX C

PARENT VOCABULARY FORMS 
Oupacien Progran

Dear Parent:

Please fill out the following information about your child.

Child's inftials:

School:

Birthdate:

Sex:

Number of children in family:

How many siblings are older than the chtlo?

How many stolings are younger than the child?

Assume that your child is unable to camunicate oy talking and must conmunicate by pointing to pictures and words. Please ilst the 110 most important words your child would need in order to communicate effectively during regular day. Before completing the 11st, you may find it helpful to listen to your child for a little while.

Attached is a form with blanks for your 110 words. Pledse put a check in the column called "Essential Nords" if the word is one that must be included for dally comunication. Put a check in the column called "Extra Hords" if the word would be nice to include, but is not es sentlal for dafly comunication. oifferent foms of the same word (plurals, -ing endings) can be listed as separate words.

Please all the completed foras to me in the attached self-addressed stamped envelope.

Thank you for your time and consideration.

Sincerely,

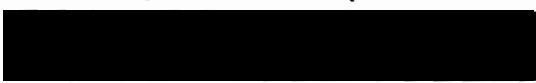

Manie Fried-oken

Home Address:

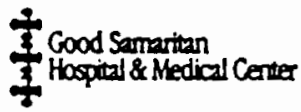




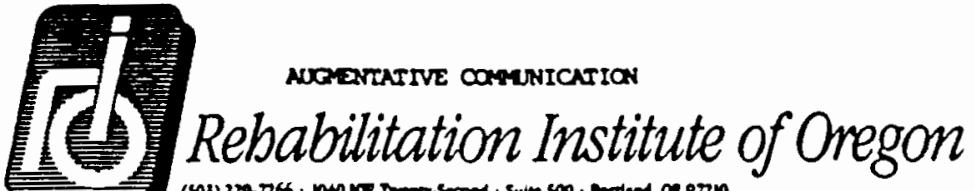

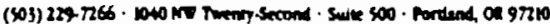

aupasous fropurm

Dear Parent:

Please fill aut the following information about your child.

Child's initlals:

Birthdate:

Sex:

Number of children in tanily:

How many siblings sre older?

How many siblings are younger?

How many hours each day do you spend with your child?

What is your relationship to the child?

What is your child's maln mathods of camrunication?

What focm(s) of augmentative communlcation has your chlld used in the pest?

Bave you and/or your child's theraplsts/teachers prepared a vocabulary list already?

If yes, how many words and/or phrases are Included in the list?

Please list the 110 most luportant words your child needs in order to communicate effectivaly during a regular day. Some parents tind it eary to thinks of this 1ist as the 110 words that thair chlld would use a lot if he/ato could talk. Before completing the Ilst, you may find it helptul to oberve your child carefully tor a inlle. If a vocabulary llst has alresdy been made tor your child, you may use the words in that list. Please put a naxt to thoes words that were previlously chosen.

Below is a foon with blanks for your 110 words. Please put a check in the colum called "Essential Hords" if the word is one that must be included for daily comminication. Put a check in the colume called "Excra words" if the word would be nice to include, but is not essential for dally comminication. Olfferent forms of the sime root word (think, thought, thinking) can bo llated as separate words. 
1.

2.

3.

4.

5.

6.

7.

8.

9.

10.

11.

12.

13.

14.

15

16.

17.

18.

19.

20.

21.

22.

23.

24.

25.

26.

27.

28.

29.

30.
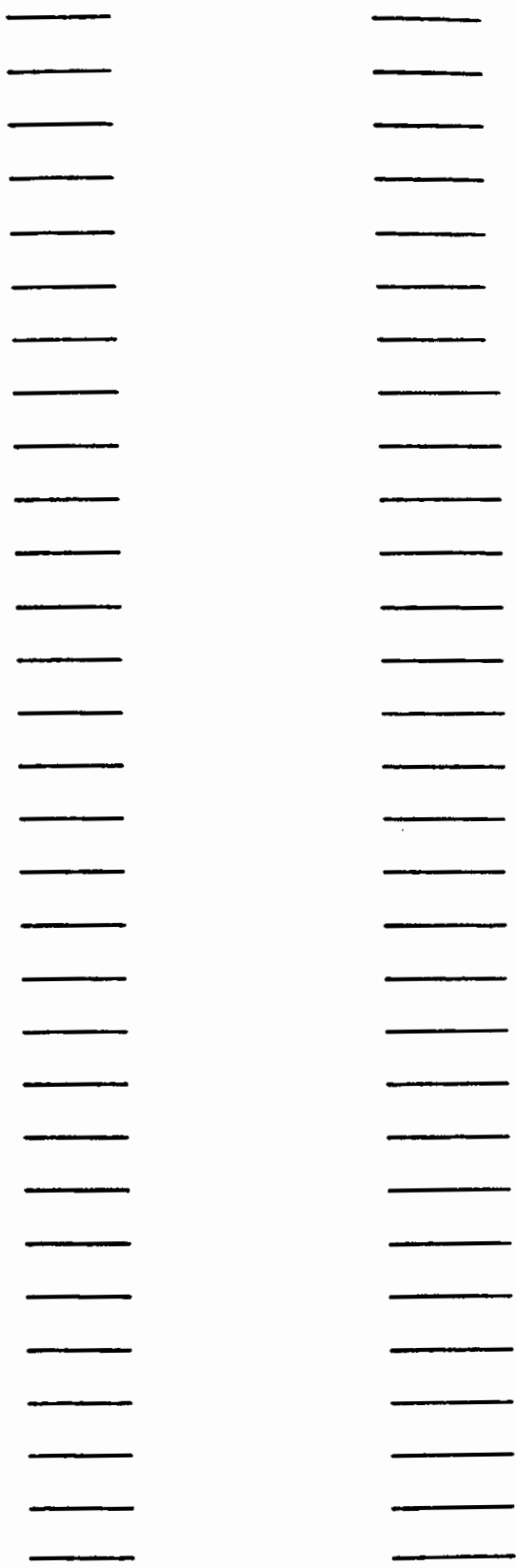
31.

32.

33.

34.

35.

36.

37.

38.

39.

40.

41.

42.

43.

44.

45.

46.

47.

48.

49.

50.

51.

52.

53.

54.

55.

56.

57.

58.

59.

60.
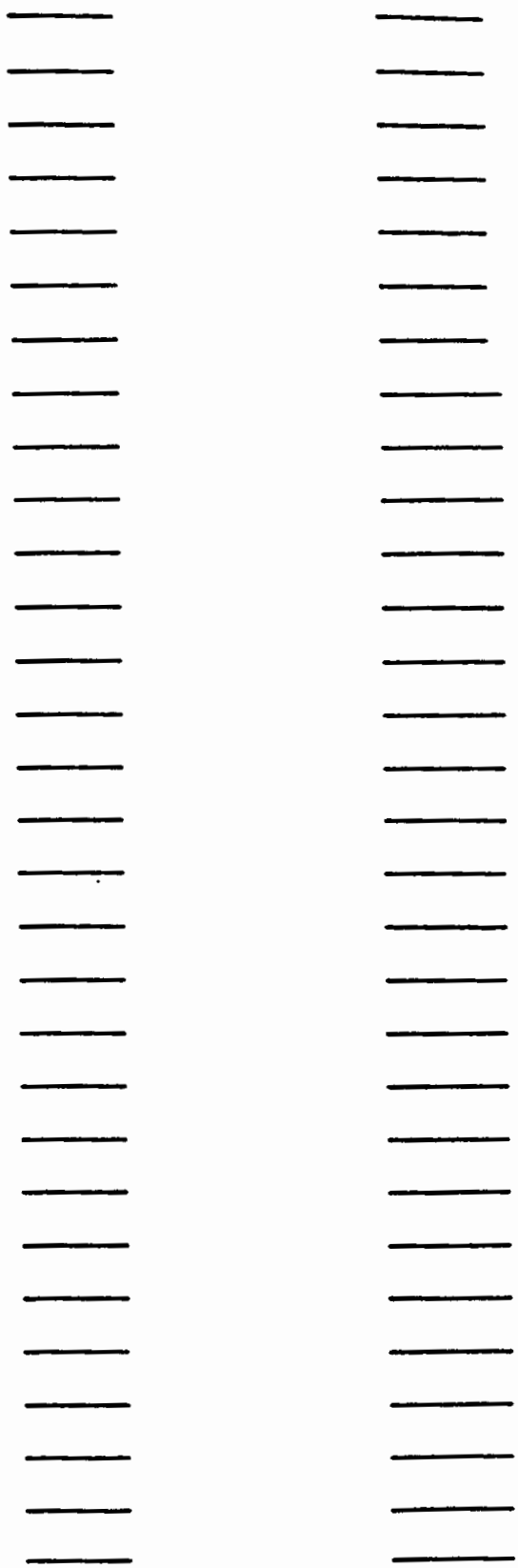
61.

62.

63.

64.

65.

66.

67.

68.

69.

70.

71.

72.

73.

74.

75.

76.

77.

78.

79.

80.

81.

82.

83.

84.

85.

86.

87.

88.

89.

90.
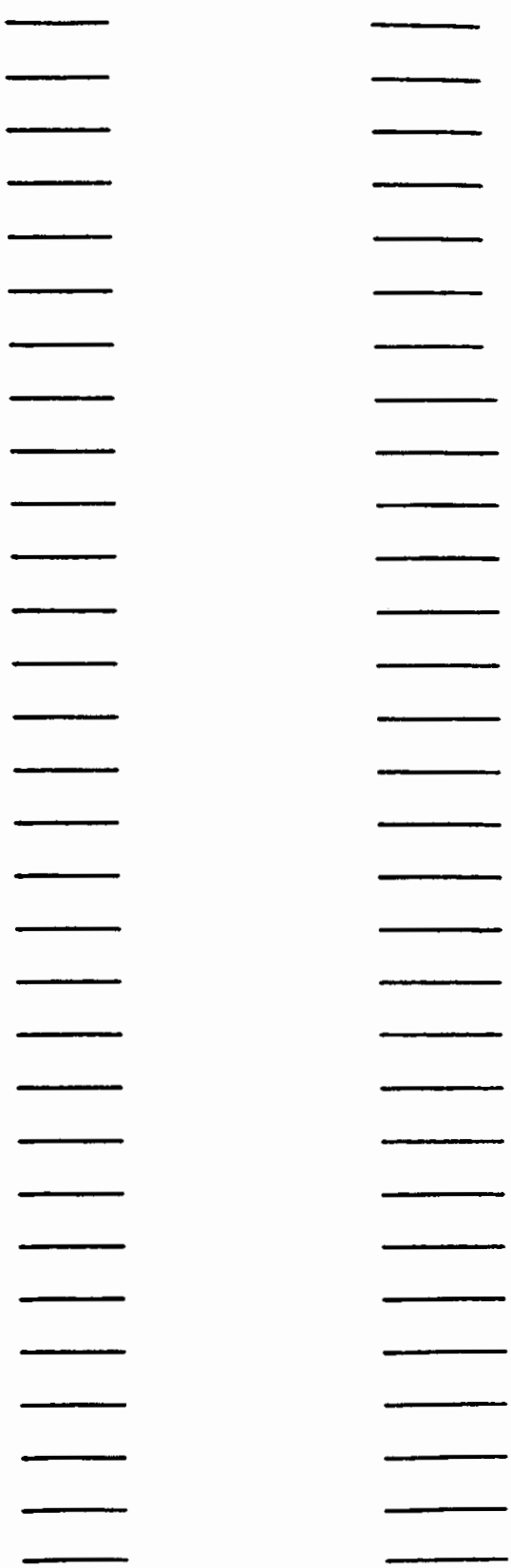
LOROS

91.

92.

93.

94.

95.

96.

97.

98.

99.

100.

101.

102.

103.

104.

105.

106.

107.

108.

109.

110.
ESETTLL LONOS

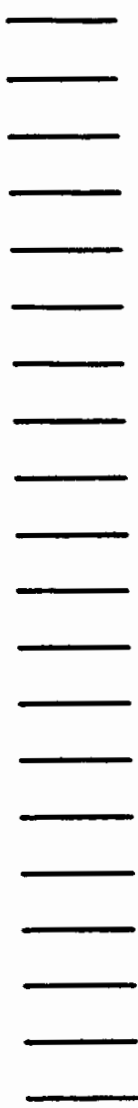

\section{DRRA horos}

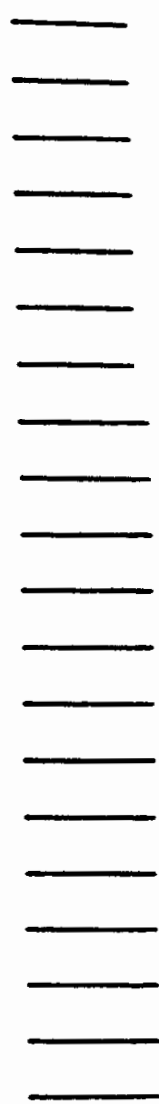


APPENDIX D

GUIDELINES FOR COLLECTING LANGUAGE SAMPLES 


\section{GUIDELINES FOR COLLECTING LANGUAGE SAMPLES}

We ask you to elicit a language sample that contains at least 1000 intelligible, transcribable whole words. We suggest that you tape about 60 to 90 minutes of spontaneous speech. This could be done in two or three sessions. Indicate the child's initials and the dates of the recordings on the cassette.

We are trying to elicit common words that are used in a child's daily environment. We have found that a doll house and dolls create a familiar family setting for frequent vocabulary. A Fisher-Price "Little People's" doll house with dolls, cars and furniture were the stimulus materials used with the speaking ambulatory control subjects.

Introduce a number of routines that are included in a child's daily life. These could include:

- waking up and getting dressed

- making or eating breakfast/lunch/dinner

- going to school or day care

- going to the store

- family outings

- watching TV

- playing - toys and games

- snacks

- nap time

- bedtime - baths, bedtime story, etc.

Some children are responsive to these suggestions and will talk about them. Others will not be directed by an adult and will introduce the routines that they want to talk about. Don't be too concerned if the child refuses to talk about these routines!

Please repeat those utterances which you feel might be unintelligible to the transcriber. It is better to repeat too much than not repeat at all! please note the location and dates of the samples and any comments on the data collection form.

If you have any questions or concerns about the guidelines, feel free to call Dr. Melanie Fried-oken or Lillian More, collect, at (503) 229-7266. We thank you for your help. 


\section{AFPENDIX E}

PROCEDURES FOR SELECTING 100 SINGLE WORDS

FROM THE 110-WORD VOCABULARY LIST 


\section{PROCEDURES FOR SELECTING 100 SINGLE WORDS}

FROM THE 110-WORD VOCABULARY LIST

To obtain 100 words:

1. Words that were checked off as "essential" by the caregiver were counted first, beginning with the first "essential" word listed.

2. Words that were checked off as "extra" by the caregiver were counted next, beginning with the first "extra" word listed.

3. Words that were not checked as being either "essential" or "extra" were treated as "extra" words.

4. Words that appeared twice on the same list were only used once.

5. The morphemes plural "s", $n$ 't, 'll, 're, 's, 've, ' $m$, and 'd were entered as separate words.

6. If more than one word appeared on a line, each word was counted as a separate word.

7. Two words that represented a single concept, such as "thank you" were hyphenated and counted as one word.

8. Once 100 words were selected, the remaining words were disregarded. 


\section{APPENDIX F}

TRANSCRIPTION AND EDITING GUIDELINES 
TRANSCRIPTION AND EDITING GUIDELINES

1. Omit first 50 utterances

2. Transcribe 1000 words

3. Omit:

4. Include:
A. False starts
B. Repetitions that are reformulations or pause fillers
C. Pause fillers (um, uh, well)
D. Excogitations unless used as questions (let's see, you know)
E. Sentence starters (now, so, oh)
F. Nonlinguistic sounds
G. Confirmations of the examiner's repetition of the child's previous utterance (uh huh, yeah)

A. Phrases that are abandoned before completion

B. Repetitions used for emphasis, mark progress, or that are not reformulations or fillers

C. Excogitations used as question (see, you know)

D. Every other conjunction when stringing together several clauses

E. "Oh" when used in giant forms (oh dear, oh my)

F. Yes/no responses to examiner's yes/no questions

G. "Okay" when used as an acknowledgement

H. "Uh-oh" and "Oops"

I. Early appearing catenatives

5. Count contractions as two words

6. Count the following morphemes as separate units:

' $m$, 's, 're, 'll, s (plural), n't, 'd, 've

7. Transcribe misarticulated words in correct adult form

8. Precede child forms with an "*" (goed, taked)

9 . Precede proper nouns with an " " 